\title{
A Distributed Wireless Heat Monitoring System for Early-Fire Detection and Prevention
}

\author{
Moses Oluwafemi Onibonoje*, Adedayo Olukayode Ojo, Temitayo Emmanuel Fabunmi \\ Department of Electrical Electronic and Computer Engineering, Afe Babalola University, Nigeria
}

Received August 9, 2019; Revised October 9, 2019; Accepted October 17, 2019

Copyright $@ 2019$ by authors, all rights reserved. Authors agree that this article remains permanently open access under the terms of the Creative Commons Attribution License 4.0 International License

\begin{abstract}
Fire outbreak contributes greatly to loss of lives, properties and valuables. In order to avert such losses, reliable fire detection, notification, and prevention systems are crucial. Heat, the common indicator for fire development, requires to be monitored and controlled in a flammable environment. This paper has therefore developed a distributed approach to the detection and prevention of fire development by monitoring the inducing heat, smoke and early fire. The study proposes a model for the heat sensing and also for the control function of the system. It designs and implements the four sensing nodes, one base node, and the control and alarm system with resourceful hardware devices. The heat and smoke status of the environment is relayed for prompt action through a local user window on the administrator's personal computer (PC) and mobile phone. The local user interfaces and the internet cloud are designed for data relay and recording. The system is tested and evaluated for real-time deployment and operations. The resulting data are analyzed and reported.
\end{abstract}

Keywords Fire Detection, Real-Time, Wireless, Prevention, Heat Monitoring

\section{Introduction}

In recent times, the loss of lives and properties to fire outbreaks has been on the increase. Fire is arguably one of the most dangerous threats to commercial enterprise due to its speed of spread and shattering caustic power. An uninhibited fire could wipe out an entire edifice within moments. In the course of time, environment or structures damaged can be rebuilt or repaired, while stolen goods can be recovered. However, valuable items consumed by fire are unrecoverable. Forest, fields and stored agricultural produce are also lost to avoidable infernos which in turn contribute to global food insecurity, loss of revenue and increased climatic change [1-3]. Fire has developing stages, with heat being the common behavior indicator in all the stages. Other indicators in fire development include smoke, air track, and flame. Therefore, there is a defined relationship between fire development and heat increase as shown in Figure 1.

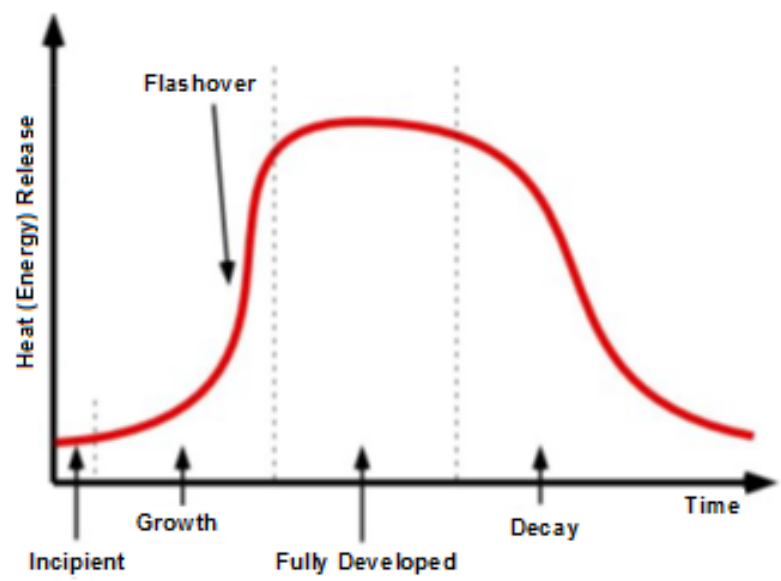

Figure 1. Relationship between heat and fire development [4]

Besides a sudden spark of fire in a flammable environment like dry forest and storage facilities for gas and fuel, an intense growing heat is a potential impetus to a pending fire outbreak. Also, no smoke is without fire. Like heat, smoke is an indicator for early developed fire $[4,5]$. Therefore, any effort towards halting the spread of a developed fire should begin with properly identifying the event, triggering an alarm, and then sending a real-time notification towards quenching it. A reliable and efficient fire detection and alarm system is a vital composite unit of every fitted enterprise [6].

The growth and spread of fire is mainly influenced by the air volume and heat transfer. Meanwhile, the major constituent factors of convective heat transfer are temperature and humidity. Fire detection and alarm systems exist in different types and options, depending on 
the specific features of the monitored area. Identifiable lapses could be established with the inventions about fire detection through heat transfer monitoring. Wireless sensor network (WSN) and internet of things (IoT) have introduced tremendous advancement in the application of the integrated capacities of sensors, wireless connectivity and internet to solving diverse problems [7-8]. Some works have also proposed the application of WSN in fire detection and management. The techniques have quite comparatively larger scale of research area than other fields [2, 4, 9-12]. However, the need for real-time monitoring, notifications, and mitigation of the early developed fire has not been adequately justified and implemented. Meanwhile, the costs of a deficient system in fire prevention can be overwhelming.

This paper develops an IoT based distributed solution to integrating WSN for the real-time heat and smoke monitoring with the aim of detecting and preventing fire outbreak and development. A model is proposed for heat monitoring and control, the system is implemented with autonomous devices, and tested for real-time solutions.

\section{Materials and Methods}

The method proposes a system model for the heat index by the nodes in the system. Then, the system is designed and implemented with hardware for the heat and smoke monitoring and control for fire prevention.

\subsection{System Model}

In order to accurately represent the physical phenomenon of fire development, this work proposes a carefully developed system model which enhances analysis and rapid understanding of the underlying process. The proposed system model is divided into two: sensing model and the control model.

\subsubsection{Sensing Model}

The model for the homogenous nodes leverages the decision and control function of the air-conditioning system on the heat index, as a function of temperature and humidity. The control or decision variable is the heat heat $_{i, t}$ within the coverage area of each sensor node $j$ over a period interval $t$, as given in equation (1).

$$
\begin{array}{r}
\text { heat }_{j, t}=a+b T_{j, t}+c H_{j, t}+d T_{j, t} H_{j, t}+e T^{2}{ }_{j, t}+ \\
f H_{j, t}^{2}+g T_{j, t}^{2} H_{j, t}+h T_{j, t} H_{j, t}^{2}+k T_{j, t}^{2} H_{j, t}^{2}
\end{array}
$$

where $T_{j, t}$ is the Temperature in and $H_{j, t}$ is the relative humidity within the coverage of sensor node. According to [13], the values of the constants are as given in Table I.
Table 1. Values of the constants for heat parameters

\begin{tabular}{|c|c|}
\hline Constant & Value \\
\hline a & -42.37900000 \\
\hline b & 2.04901523 \\
\hline c & 10.14333127 \\
\hline d & -0.22475541 \\
\hline e & $-6.83783000 \times 10^{-3}$ \\
\hline f & $-5.48171700 \times 10^{-2}$ \\
\hline g & $1.2287400 \times 10^{-2}$ \\
\hline h & $8.52820000 \times 10^{-4}$ \\
\hline k & $-1.99000000 \times 10^{-6}$ \\
\hline
\end{tabular}

The input variables for the node are temperature $T_{j, t}^{i n}$ and humidity $H_{j, t}^{i n}$ over a period interval $t$. The output variable is the indexed heat heat $_{i, t}$. The temperature and humidity within the coverage of each node must be maintained within a range of values as given by equation (2) and (3); where $T_{j, t}^{\min }, H_{j, t}^{\min }$ and $T_{j, t}^{\max }$ and $H_{j, t}^{\max }$ are the minimum and maximum values of temperature and humidity respectively. The heat is subsequently maintained within a threshold as given in equation (4), and the control action is expected to be activated when the threshold is exceeded.

$$
\begin{gathered}
T_{j, t}^{\text {min }} \leq T_{j, t}^{\text {in }} \leq T_{j, t}^{\max }, \forall(j, t) \\
H_{j, t}^{\text {min }} \leq H_{j, t}^{\text {in }} \leq H_{j, t}^{\max }, \forall(j, t) \\
\text { heat }_{j, t}^{\text {min }}<\text { heat }_{j, t}<\text { heat }_{j, t}^{\text {max }}, \forall(j, t)
\end{gathered}
$$

The variables that describe the system with each node $j$ at $t \geq 0$ are $T, H$, heat [14]. The input variables are $T$ and $H$, while the output variable is the heat. The memory in the system is the integrator whose output defines the internal state of the system, and serves as the state variable $x$. The state equation for the system is as given in equation (5).

$$
\dot{x}(t)=f\left(x, t_{j}, h_{j}, t\right)
$$

The output of the model is as described at operating point heat $=g\left(T_{j}, H_{j}\right)$ in equation (6).

$$
\text { heat }(t)=g\left(x, t_{j}, h_{j}, t\right)
$$

Using the Taylor's series approximation, the system could be described as given in equation (7).

$$
\begin{array}{r}
\text { heat }(t)=g\left(T_{j}, H_{j}\right)+\left(t_{j}-T_{j}\right) \frac{d g\left(T_{j}, H_{j}\right)}{d t_{j}}+\left(h_{j}-\right. \\
\left.H_{j}\right) \frac{d g\left(T_{j}, H_{j}\right)}{d h_{j}}+\frac{1}{2 !}\left[\begin{array}{c}
\left(t_{j}-T_{j}\right)^{2} \frac{d^{2} g\left(T_{j}, H_{j}\right)}{d T_{j}^{2}} \\
+2\left(t_{j}-T_{j}\right)\left(h_{j}-H_{j}\right) \frac{d^{2} g\left(T_{j}, H_{j}\right)}{d t_{j} d h_{j}}
\end{array}\right]
\end{array}
$$

Assumption:

$\Delta t_{j}=\left(t_{j}-T_{j}\right)$ and $\Delta h=\left(h_{j}-H_{j}\right)$ are small because the excursions around the operating point are minimal.

$$
\Delta t_{j}{ }^{m}, \Delta h_{j}{ }^{m} \cong 0(m \geq 2)
$$


Therefore, the system sensing model takes the form as given in equations (9) and (10).

$$
\begin{gathered}
\Delta \text { heat }=\text { heat }(t)-g\left(T_{j}, H_{j}\right) \\
\Delta \text { heat }=\frac{d g\left(T_{j}, H_{j}\right)}{d t_{j}} \Delta t_{j}+\frac{d g\left(T_{j}, H_{j}\right)}{d h_{j}} \Delta h_{j}
\end{gathered}
$$

\subsubsection{Control Model}

The controller model in the system is a form of a two-position or on-off mode controller as shown in Figure 2. The model will assume a non-linear ideal relay with an input of ac voltage. The input voltage to the system is a sine function with oddness and half-wave symmetry as given in equation (11).

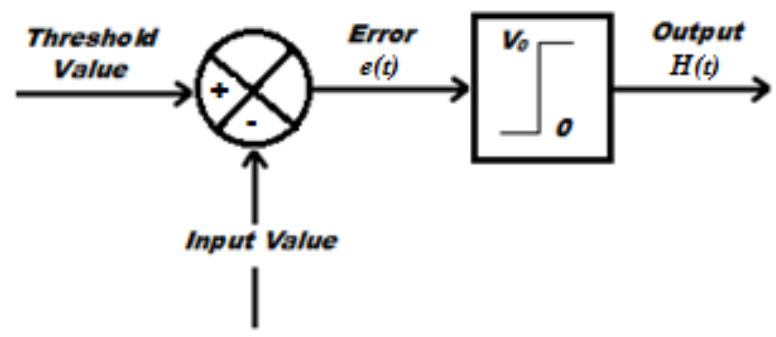

Figure 2. The controller model

$$
v(t)=V \sin \omega t
$$

The describing function of the linearized model takes the form as given in equation (12).

$$
\begin{gathered}
N(V, j \omega)=\frac{B}{V} \angle 0^{0} \\
B=\frac{4}{\pi} \int_{0}^{\frac{\pi}{2}} v(t) \sin \omega t d(\omega t) \neq 0
\end{gathered}
$$

Therefore, the describing function for the control model is as given

$$
\left\{\begin{array}{ll}
\text { heat }(t)=0, & e(t)<0 \\
\text { heat }(t)=V_{0}, & e(t) \geq 0
\end{array}\right\}
$$

$$
\begin{gathered}
B=\frac{4 V_{0}}{\pi} \\
N(V, j \omega)=\frac{4 V_{0}}{\pi V} \angle 0^{0}
\end{gathered}
$$

The model indices include $1 \leq j \leq n$ for $\mathrm{n}$ number of lines to be controlled, and $1 \leq t \leq h$ for $h$ intervals with $t$ index in hours. The models can then be expanded further, analyzed with the objective function and validated.

\subsection{Hardware Design}

The hardware unit of the system was designed and implemented in five different categories namely: sensing nodes, base node, control unit, thermal insulator and indication unit. The objectives of the hardware implementation are to develop sensor nodes with the ability to detect fire-inherent smoke and high heat index within the defined location, develop a base node with the ability to collect data from the sensor nodes and sort the information according to the timing and identification of the nodes, then develop a network system consisting all the nodes for heat index monitoring and fire detection. The block diagram of the system showing three of the five developed nodes is as shown in Figure 3.

\subsubsection{System Nodes}

The sensors in each sensor node are DHT22 to detect the temperature and humidity variation, the MQ5 to detect the fire-inherent smoke, and the flame sensor to detect the fire flame immediately it forms. The transceiver in each node is the Digimesh $2.4 \mathrm{GHz}$ Xbee with a microchip antenna, while arduino variants were designated as the microcontroller. The block diagram of each sensor node is as shown in Figure 4. 


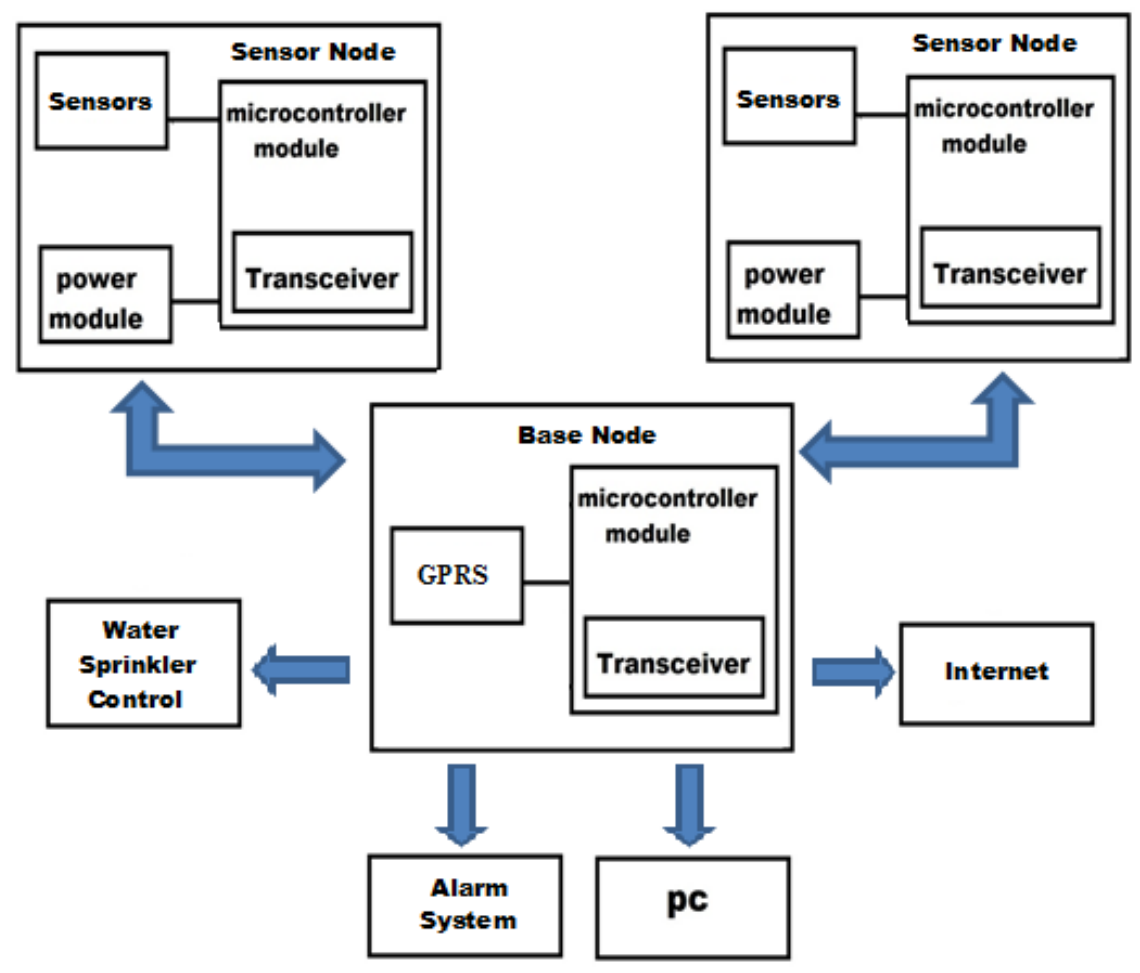

Figure 3. Block Diagram of the System Hardware

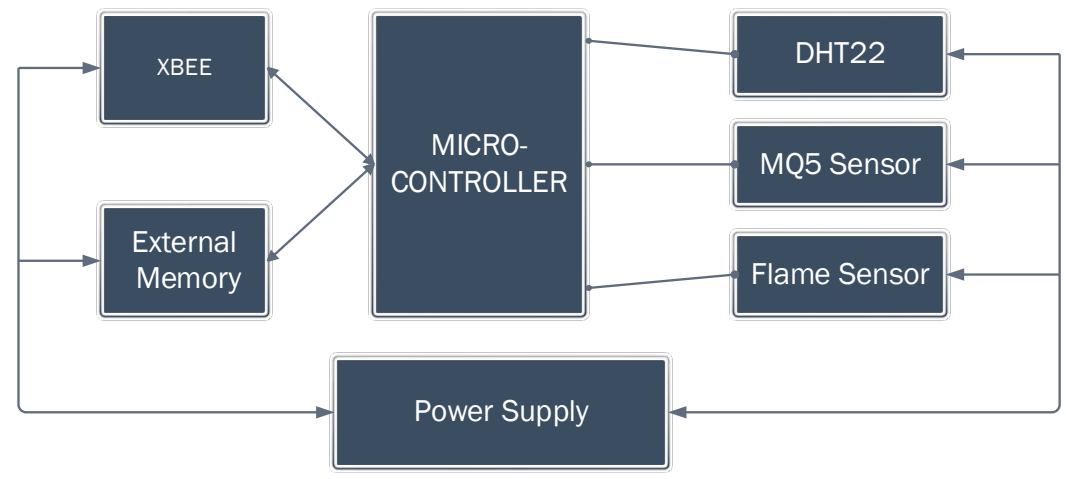

Figure 4. Block Diagram of the System Hardware

The sensor node and base node have the same components, except that the sensor node has the sensors and powered with a solar rechargeable battery, the base node has no sensor and being powered from a regulated dc source. The base node is designed to be connected to a GSM module for communication with the internet cloud and administrator's mobile phone. It is also connected to a personal computer (PC), and relay its data on the PC by a developed user interface (UI).

Also, a thermal insulator circuit is to be developed to protect the wireless devices from very high melting temperature higher than $140{ }^{\circ} \mathrm{C}$.

\subsubsection{End-User and Control Unit}

The variation in the heat index as a function of the temperature and humidity, as well as the detection of fire or otherwise is indicated on the UI, while notifications are sent to the mobile phone. Also, there is an alarm system which is on real-time standby whenever there is extreme heat index, smoke or fire outbreak. A water sprinkler is activated to operate whenever such condition is detected.

\subsection{Software Design}

The base node was programmed to coordinate the entire network by setting up the network and integrate all the sensor nodes into the network, collect data for the nodes, analyze the data, and take the appropriate decision on the data and the control units. The flowchart for the base node and the network is as shown in Figure 5, while the flowchart of the senor node programming is as shown in Figure 6 . The block diagram of the algorithm for the user interface as designed with LabVIEW is as shown in Figure 7. 


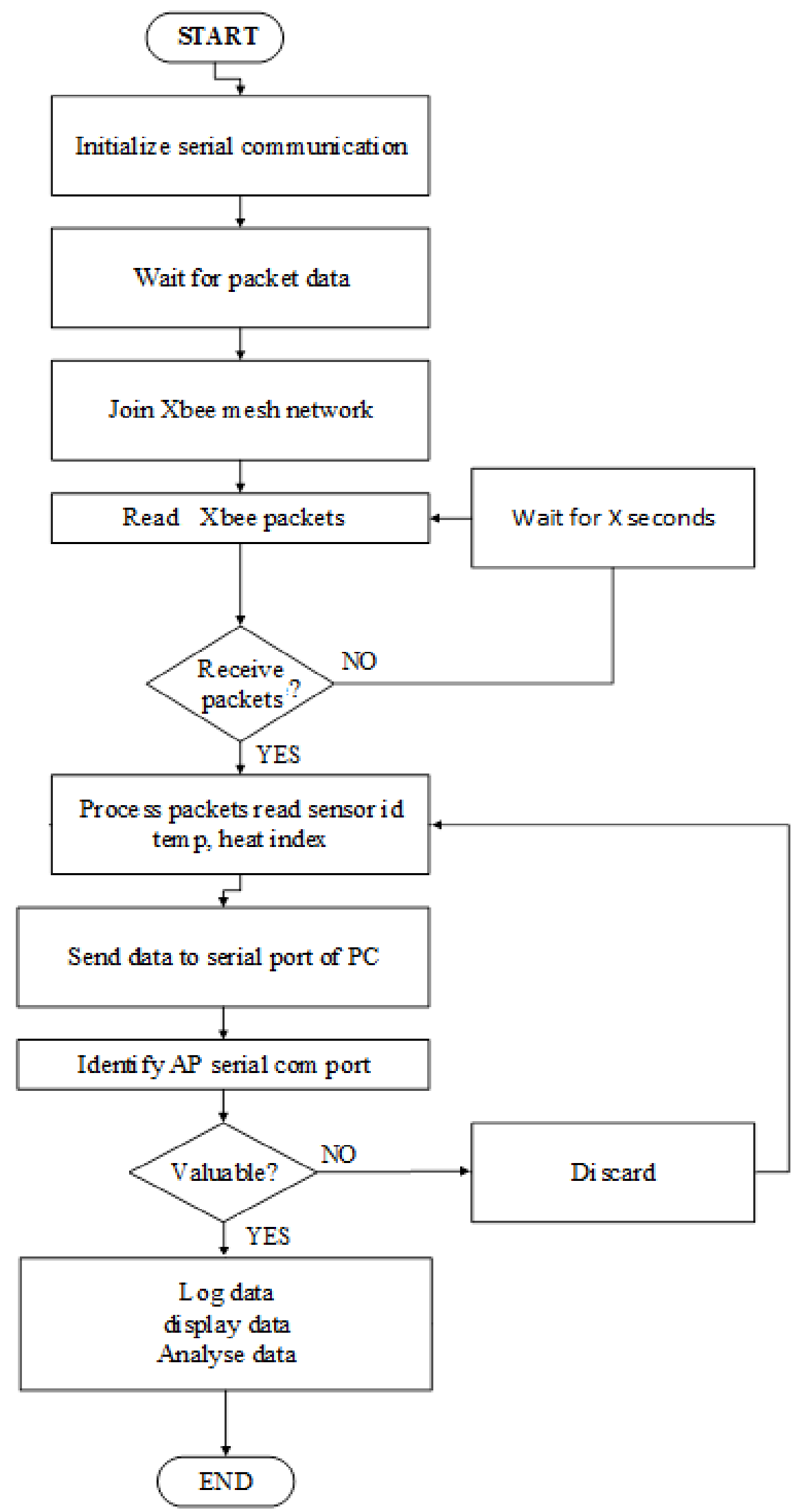

Figure 5. The Flowchart of the Base Node and System Network 


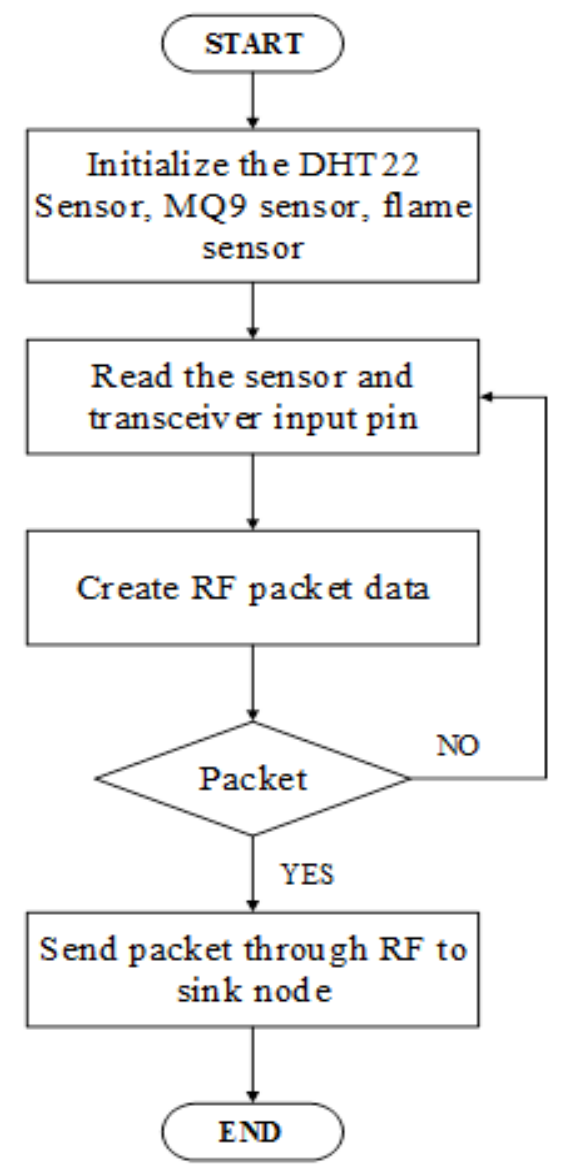

Figure 6. The Flowchart for Programming the Sensor Node

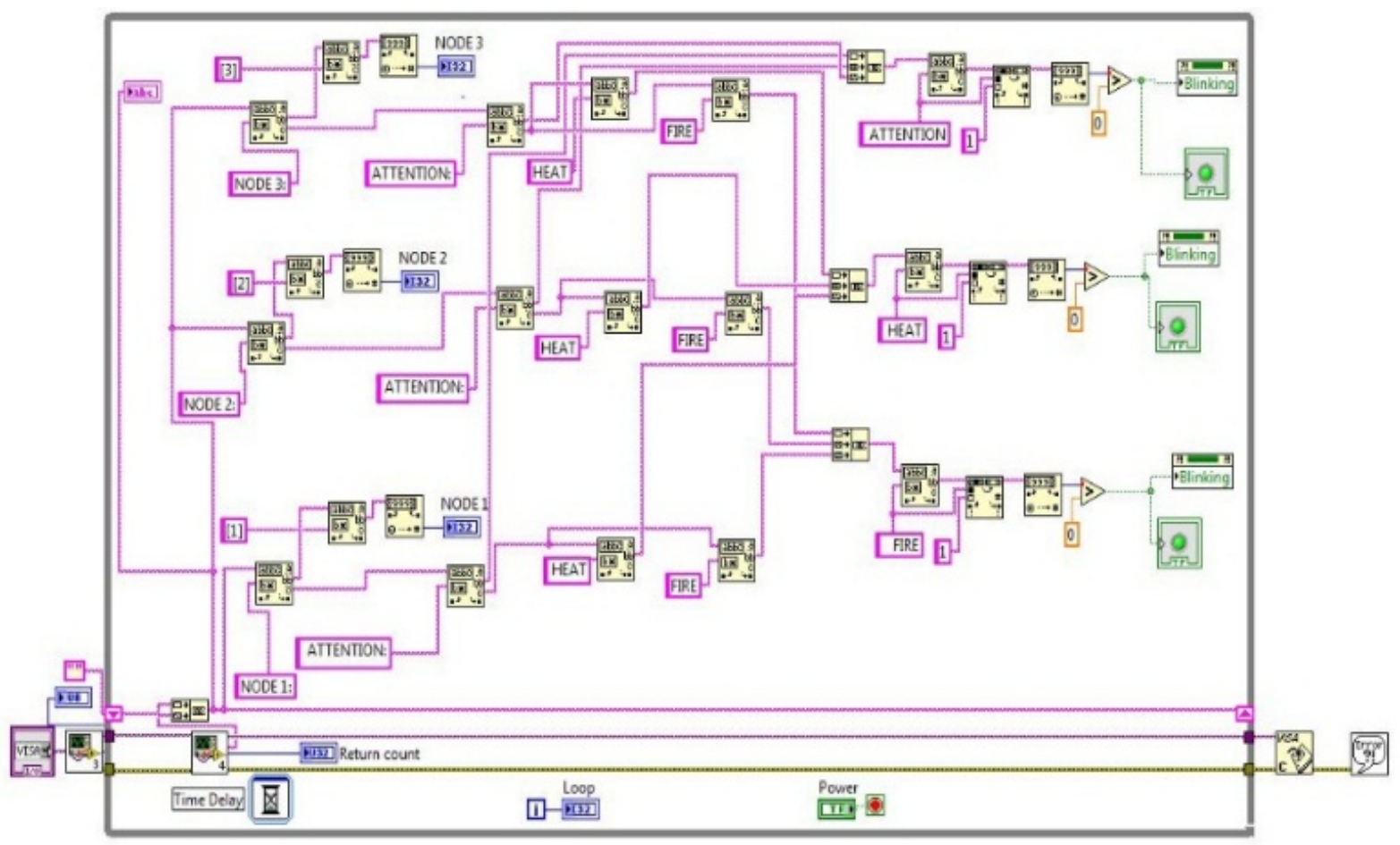

Figure 7. Block Diagram of the User Interface 


\section{Results and Discussion}

A system consisting of five wireless nodes was developed, consisting of four sensor nodes, one base node, one control unit, an alarm system and three user interfaces.

\subsection{The Developed Node Units}

The nodes were developed and integrated within a network. The sensor nodes as shown in Figure 8(a) were wirelessly connected into the network created by the base node as shown in Figure 8 (b). The system was tested for the different scenarios with two sensor nodes as shown in Figure 8 (c), and the resulting responses of the system are as shown on the UI in Figure 9.

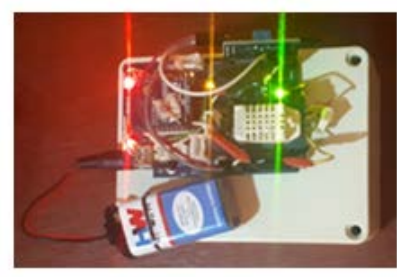

(a)

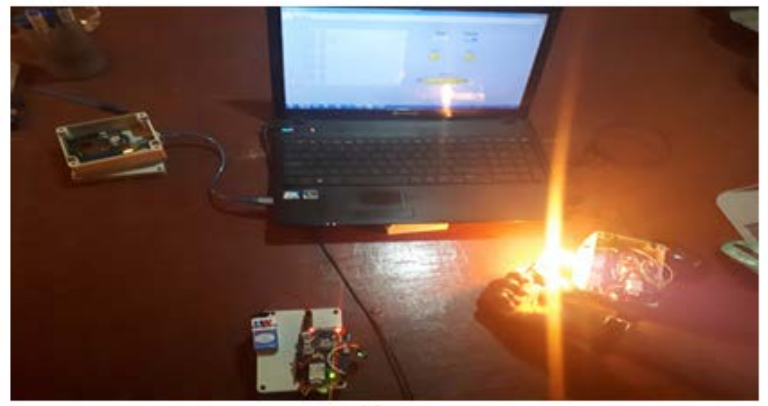

(c)

Figure 8. The Developed System, (a) Sensor Nodes, (b) Base Node, (c) The Networked System during Testing.

\subsection{User Interface and Testing Results}

The LabVIEW-developed user interface for the distributed system indicate the condition of the monitored area with respect to fire-inherent heat and fire flame formation. If any of the parameters is measured safely, the corresponding indicator shows 'green'; and shows 'amber' whenever it measures above the threshold. The fire-inherent heat has a threshold of $200^{\circ} \mathrm{C}$, and the fire occurrence is detected when the flame glows. The result of the testing showed that when the heat was below $200^{\circ} \mathrm{C}$ and there was no flame, all the indicators turned green as shown in Fig 9 (a). When the heat index was averagely $225^{\circ} \mathrm{C}$ and there was no fire, the heat and the alert indicators turned amber while the fire indicator remained green as shown in Fig 9 (c). Finally, immediately the fire flame glowed, all the indicators turned amber. The results were streamed in real-time on the user interface as shown in Fig 9, while notifications were sent to the mobile phone.

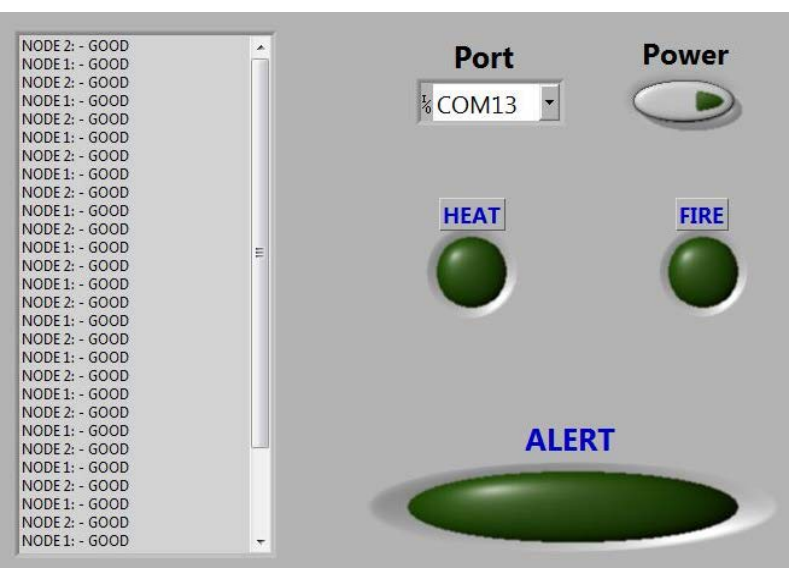

(a)

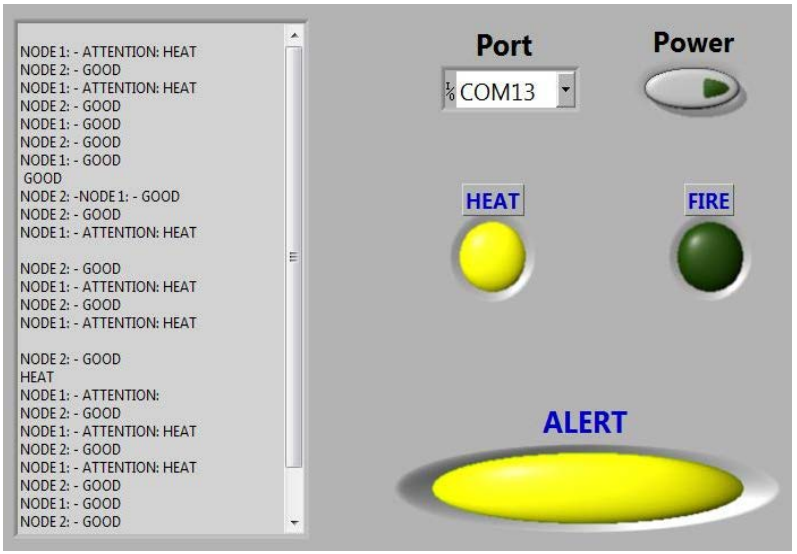

(b)

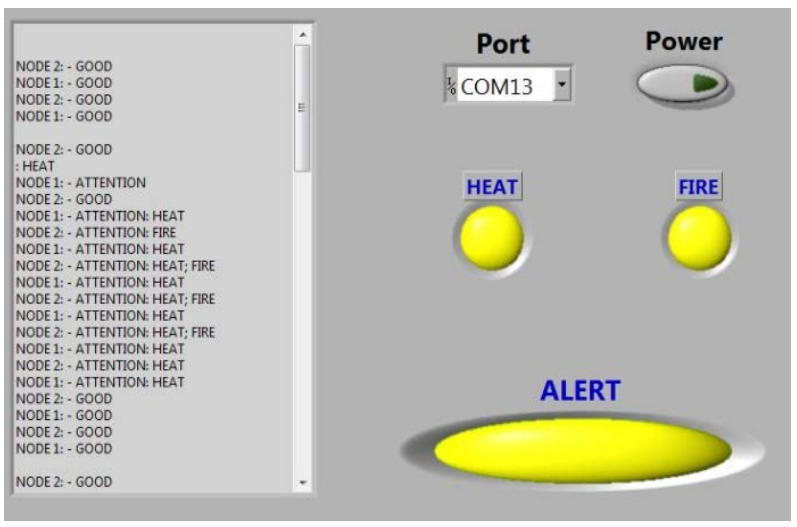

(c)

Figure 9. User Interface (UI) Showing the Indication with (a) Normal Condition, (b) Extreme Heat but No Fire, and (c) Extreme Heat and Fire

\subsection{Resulting Data}

In a normal environmental heat condition, the heat parameter is relatively constant as shown in Figure 10(a). As the environmental heat increases, both the actual recorded values and the simulated model parameters increase, as shown in Fig 10(b). The simulated and actual values are very close and follow the same trend, thereby justifying the mode adopted. 


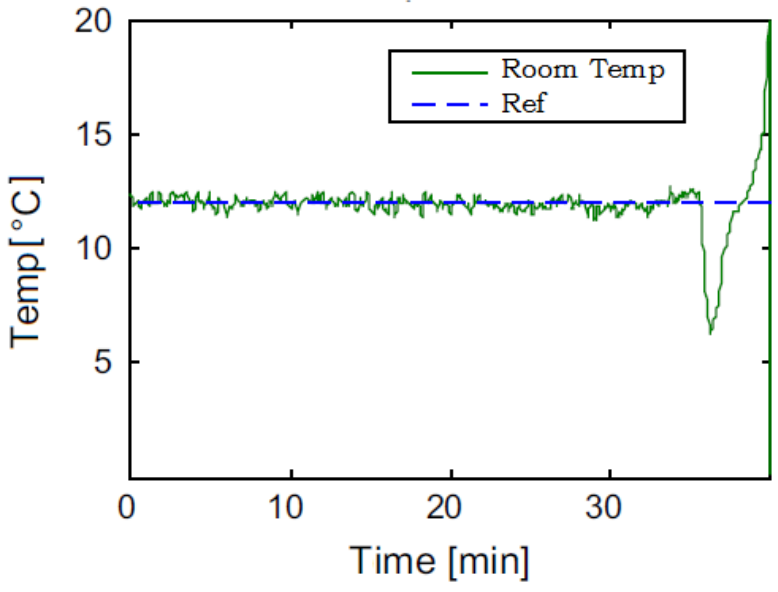

(a)

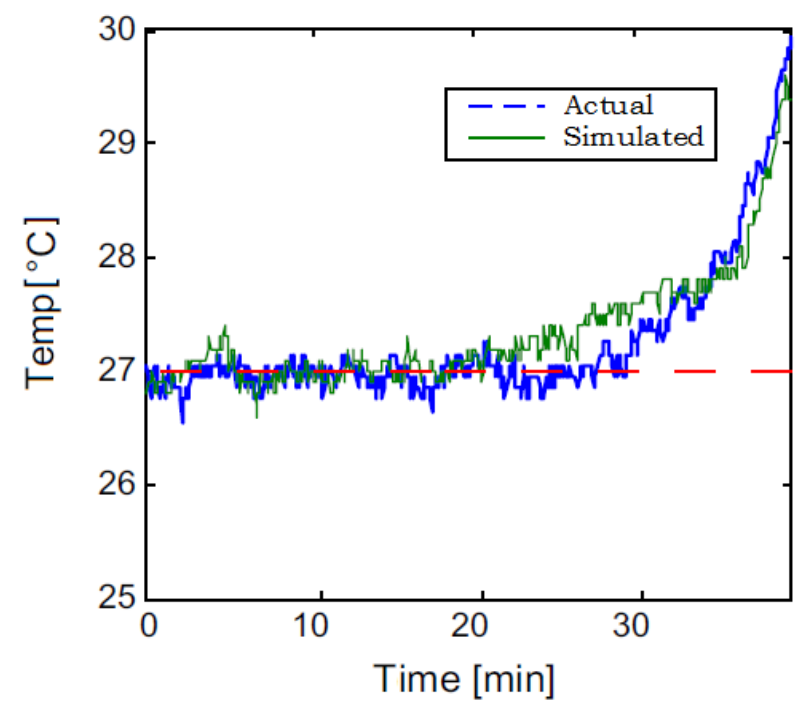

(b)

Figure 10. Resulting heat data (a) Normal room condition, (b) Increasing room heat

\section{Conclusions}

In order to ensure early fire detection, notification and prevention, a distributed system of wireless sensor nodes have being modelled, designed and implemented. The system operates with distributed approach by optimally locating the sensor nodes at various point within the protected area, and wirelessly communicate the measure of the heat variation and fire identification in each location to the base node. The base node analyses the transferred data, operates the control and alarm unit accordingly, and relays the status and notifications to the users through the user interface, mobile phone and internet hub. The simulated result of the constituent parameters of the fire-inducing heat gives a very good agreement with the result acquired from the developed and deployed system. Hence, a good distributed approach in this study. The system provides a very reliable and latest technology for detecting heat and smoke during the developing stage and also gives notification and alert for the users if and when the fire develops. The uniqueness of the developed system include reliability, real-timeliness, distributed and wireless intervention in its operations. Also, the study has provided the template for researching into the modeling of heat parameter in fire detection and prevention. A further research is recommended for the ultimate automated water sprinkler in the on the specific area of fire outbreak within the monitored perimeter.

\section{REFERENCES}

[1] V. Chowdary and M. K. Gupta, "Automatic Forest Fire Detection and Monitoring Techniques: A Survey," in Intelligent Communication, Control and Devices, Springer, pp. 1111-1117, 2018.

[2] A. Sardouk, M. Mansouri, L. Merghem-Boulahia, D. Gaiti, and R. Rahim-Amoud, "Crisis management using MAS-based wireless sensor networks," Comput. Networks, vol. 57, no. 1, pp. 29-45, 2013.

[3] M. O. Onibonoje, O. Folorunso, A. Ajibade, and K. A. Adeniji, “An Integrated Approach to Automated Control for Air-Conditioned Home Apartments using Wireless Sensor Network,” Indian J. Sci. Technol., vol. 9, no. 40, pp. 1-9, 2016.

[4] A. Clemente, J. Mart'’linez-de Dios, and A. O. Baturone, “A wsn-based tool for urban and industrial fire-fighting," Sensors, vol. 12, no. 11, pp. 15009-15035, 2012.

[5] J. Cheng, Y. Gao, N. Zhang, and H. Yang, "An Energy-Efficient Two-Stage Cooperative Routing Scheme in Wireless Multi-Hop Networks," Sensors, vol. 19, no. 5, p. 1002, 2019.

[6] A. R. Ulucinar, I. Korpeoglu, and A. E. Cetin, “A Wi-Fi cluster based wireless sensor network application and deployment for wildfire detection,” Int. J. Distrib. Sens. Networks, vol. 10, no. 10, p. 651957, 2014.

[7] M. O. Onibonoje and T. O. Olowu, "Real-time remote monitoring and automated control of granary environmental factors using wireless sensor network," in 2017 IEEE International Conference on Power, Control, Signals and Instrumentation Engineering (ICPCSI), 2017, pp. 113-118.

[8] M. O. Onibonoje, "Design of Power Optimization Module in a Network of Arduino-Based Wireless Sensor Nodes," 2019.

[9] A. Molina-Pico, D. Cuesta-Frau, A. Araujo, J. Alejandre, and A. Rozas, "Forest monitoring and wildland early fire detection by a hierarchical wireless sensor network," J. Sensors, vol. 2016, 2016.

[10] C. Hartung, R. Han, C. Seielstad, and S. Holbrook, "FireWxNet: A multi-tiered portable wireless system for monitoring weather conditions in wildland fire environments," in Proceedings of the 4th international conference on Mobile systems, applications and services, 2006, pp. 28-41. 
[11] X. Yan, H. Cheng, Y. Zhao, W. Yu, H. Huang, and X. Zheng, "Real-Time identification of smoldering and flaming combustion phases in forest using a wireless sensor network-based multi-sensor system and artificial neural network,” Sensors, vol. 16, no. 8, p. 1228, 2016.

[12] C. E. Premal and S. S. Vinsley, "Image processing based forest fire detection using YCbCr colour model,” in 2014 International Conference on Circuits, Power and Computing Technologies [ICCPCT-2014], 2014, pp. 12291237.

[13] US Gov, “The relationship of temperature and humidity for weather condition.” [Online]. Available: https://www.weat her.gov/ama/heatindex. [Accessed: 03-Feb-2019].

[14] K. Ogata, No Title, 5th ed. Prentice Hall, 2010. 